\title{
Interface de Controle por Métodos de Autonomia Adaptável Deslizante para Robôs de Inspeção
}

\author{
Piatan Sfair Palar ${ }^{1}$, André Schneider de Oliveira ${ }^{1}$ \\ ${ }^{1}$ Universidade Tecnológica Federal do Paraná (UTFPR) \\ Av. Sete de Setembro 3165 - Curitiba - PR - Brazil \\ piatan@alunos.utfpr.edu.br, andreoliveira@utfpr.edu.br
}

Resumo. Este trabalho realiza uma implementação de uma interface humanorobô para um robô escalador de inspeção de cordões de solda em tanques de armazenamento na indústria petroquímica. Para realizar esta interface, primeiramente foi apresentada uma pesquisa do estado da arte em Interação HumanoRobô, Autonomia, Autonomia Variável e Modos de Autonomia em sistemas robóticos e sistemas autônomos em geral. Após isto, um sistema controlador de rádio frequência transmissor-receptor comumente utilizado para comandar gruas, guindastes e pontes rolantes foi especificado e adaptado para controlar o robô. um driver foi desenvolvido para tornar este controlador compativel com o sistema robótico ROS (Robot Operating System), utilizado neste trabalho. Para auxiliar no controle e adquirir mais dados de entrada do operador, foi adicionado um bracelete eletromiográfico comercial chamado Myo. Este bracelete é utilizado no antebraço e é capaz de detectar gestos do operador e ângulos de rotação do braço. As informações do controle industrial e do bracelete são utilizadas para comandar o robô através de um controlador Fuzzy. Este controlador atua na variação da autonomia durante a operação do robô, utilizando como entrada dados da velocidade angular aplicada no controle industrial, leitura de eletromiografia, posição do cordão de solda no tanque de armazenamento e os ângulos de rotação executados pelo antebraço do operador, gerando um sistema que é capaz de reconhecer a habilidade e corrigir erros do operador em tempo de operação. A saída do controlador Fuzzy é o modo de autonomia a ser aplicado no robô. Os modos aplicados foram: Manual, onde o operador controla a velocidade angular e linear do robô; Compartilhado, onde as velocidades angular e linear do robô são divididos entre o operador e o sistema autônomo do robô; Supervisório, onde o robô controla a velocidade angular, mantendo-se sobre o cordão de solda, e o operador controla a velocidade linear; e Autônomo, onde apenas o ponto final é definido pelo operador e o robô controla as velocidades linear e angular. Estes modos além do modo de Autonomia Variável foram analisados através de experimentos com o robô em ambiente simulado, demonstrando a utilidade de cada um destes modos em situações diversas.

Abstract. This work implements a human-robot interface for a climbing robot for inspecting weld beads in storage tanks in the petrochemical industry. To accomplish this, first a research on the state-of-the-art of Human-Robot Interaction, Autonomy, Sliding Autonomy and Levels of Autonomy in robotics systems and autonomous systems was presented. Then, an industrial joystick that works with radio frequency with an transmitter and a receiver, commonly used 
to move cranes and hoists, was specified and adapted to control the robot. A driver was developed to make this joystick compatible with the Robot Operating System - ROS, used in this work. To add more control and input data from the operator, a electromyographic armband called Myo was appended to the system. This armband is worn in the forearm and is capable of detecting gestures from the operator and rotation angles from the arm. Information from the industrial joystick and the armband are used to control the robot via a Fuzzy controller. This controller works in the sliding autonomy during the robot operation, using as inputs data from the angular velocity of the industrial controller, electromyography reading, weld bead position in the storage tank and rotation angles executed by the operator's arm, to generate a system capable of recognition of the operator's skill and correct mistakes from the operator in operating time. The output from the Fuzzy controller is the level of autonomy to be used by the robot. The levels implemented are: Manual, where the operator controls the angular and linear velocities of the robot; Shared, where the velocities are shared between operator and the autonomous system; Supervisory, where the robot controls the angular velocity to stay in the weld bead and the operator controls the linear velocity; and Autonomous, where an end point is defined by the operator and the robot controls both linear and angular velocities. This levels of autonomy along with the proposed sliding autonomy are then analyzed through robot experiments in a simulated environment, showing the purpose of each one of these modes.

Este trabalho é o resumo da dissertação de mestrado orientada pelo professor André Schneider de Oliveira e defendida no Programa de Pós-graduação em Engenharia Elétrica e Informática Industrial, da Universidade Tecnológica Federal do Paraná em 10 de Julho de 2020. Esse documento tem por finalidade apresentar a dissertação de mestrado ao Concurso de Teses e Dissertações em Robótica (CTDR-2021), para concorrer na categoria de melhor dissertação de mestrado. O documento de dissertação completo pode ser acessado em https://bit.ly/3jtAu6x. 


\section{Introdução}

Na indústria petroquímica, tanques de armazenamento e vasos de pressão são comumente utilizados para guardar fluidos como petróleo e derivados. Estas estruturas são formadas através de processo de soldagem e sua integridade é de importância vital, uma vez que os fluidos armazenados podem estar sob alta pressão e temperatura, expondo operadores, estruturas e o meio ambiente à riscos. Para diminuir estes riscos, inspeções preventivas periódicas nos cordões de solda presentes nos tanques esféricos e vasos de pressão são necessárias. Para realizar estas inspeções, ensaios não destrutivos (END) são utilizados, e entre eles, o ultrassom é a técnica comumente empregada devido à sua capacidade de detectar com precisão a presença de descontinuidades no cordão de solda. Nestes ensaios o operador verifica o ambiente e identifica possíveis falhas nos cordões de solda da estrutura.

É necessário o desenvolvimento de uma interface para um operador especializado poder comandar um robô de inspeção durante sua tarefa em tanques de armazenamento. Esta tarefa por sua vez pode consistir em diversas outras, cada uma com sua necessidade especial de autonomia. Ao realizar-se um ensaio não destrutivo por ultrassom phasedarray, o operador pode necessitar retornar por um percurso, passar mais lentamente em outros, ou simplesmente realizar toda a inspeção de uma só vez. Diferentes operadores com diferentes níveis de habilidade também podem necessitar de mais ou menos auxílio para comandar o robô durante as tarefas de inspeção. A motivação deste trabalho é propor um método que auxilie o operador em qualquer caso durante uma inspeção, dando mais liberdade para o operador se concentrar na inspeção através da aplicação de técnicas de autonomia variável. Na dissertação completa constam alguns exemplos de robôs utilizados atualmente para inspeção de diversos sistemas.

O objetivo principal desta dissertação é o de desenvolver um sistema que, com o auxílio de técnicas inteligentes, empregue os conceitos de Autonomia Variável para selecionar o melhor modo de atuação a ser aplicado de maneira online, durante a inspeção por um robô autônomo de cordões de solda em vasos de pressão. 


\section{Fundamentação Teórica}

\subsection{Interação Humano-Robô}

A Interação Humano-Robô, segundo [Goodrich and Schultz 2007] pode ser definida como um campo de estudos que compreende desde a primeira concepção até o desenvolvimento final de robôs que interagem com humanos física, afetiva ou socialmente. Alguns tipos de robôs industriais, manipuladores robóticos, carros autônomos, robôs assistentes e robôs de resgate são alguns exemplos de robôs que operam em comunicação e colaboração com humanos [Lasota et al. 2017]. A comunicação ocorre quando o robô informa o operador sobre o ambiente ou a intenção de suas ações. Esta ação pode acontecer de maneira visual, sonora ou háptica. A comunicação pode ocorrer também no outro sentido, com o operador influenciando ações e movimentos do robô [Losey et al. 2018]. Já a colaboração ou cooperação entre humanos e robôs é um conceito que representa a realização de tarefas por estes agentes atuando em conjunto, utilizando as habilidades mais adequadas de cada um.

$\mathrm{Na}$ indústria, a Interação Humano-Robô pode ser observada em processos como colaboração para movimentação de manipuladores em processos de montagem, orientação automática para robôs guindastes e colaboração em processos de rebitagens. Tecnologias como detecção de pessoas e objetos em ambientes 3D e reconhecimento de gestos podem ser utilizadas para o cumprimento destas tarefas [Tellaeche et al. 2015].

Em casos de situações de desastres, por exemplo, robôs podem ser destacados para lugares perigosos e estarem sendo teleoperados de uma estação segura por um operador. Esta distância porém, gera desafios para a operação, como atraso de comunicação e dificuldade em visualizar e analisar a situação [Jiang and Arkin 2016]. Uma nova área de pesquisa começou então a ser estudada, definindo regras para o nível de autonomia que os robôs assumem em determinadas tarefas e em situações de emergência ou com problemas na sua operação normal.

\subsection{Autonomia}

Uma das mais completas definições de autonomia, que leva em conta o aspecto social de um agente, é a noção de que um agente é autônomo quando tem a capacidade de escolher agir de maneira contrária às escolhas de outros agentes [Beavers and Hexmoor 2004]. Um agente pode possuir então diversos graus de autonomia, determinados por quanto de suas decisões são influenciadas por outros agentes. Uma revisão do estado da arte sobre níveis de autonomia pode ser encontrada no trabalho completo.

Nos casos onde estes níveis são alterados durante a operação de maneira online gera-se o que em inglês é chamado na literatura especializada como Sliding Autonomy, Sliding Scale Autonomy, Adjustable Autonomy ou Mixed Initiative que traduzidos para o português trazem o conceito de Autonomia Variável ou Deslizante. No contexto da robótica, estes níveis geralmente são reduzidos a 3 ou 4 . 


\section{Implementação da Interface Humano-Robô}

\subsection{Robô Autônomo de Inspeção - AIR-1}

O Robô Autônomo de Inspeção, ou AIR-1 (Autonomous Inspection Robot 1), é um robô escalador que possui diversos sensores para a percepção do ambiente. Para este trabalho, as fontes de percepção utilizadas foram o sensor de perfil LRS36/6 e uma unidade inercial IMU AHRS-8.

A arquitetura inicial e mais informações sobre o AIR-1 podem ser encontradas nos trabalhos de [Rovani 2013], [Espinoza 2014] e [Rosa and Gnoatto 2015]. Neste trabalho foi utilizada a versão virtual deste robô no simulador V-REP.

\subsection{Dispositivos de Entrada}

\subsubsection{Joystick Industrial}

Um joystick industrial, comumente usado para controlar pontes rolantes, gruas de construção e guindastes, foi especificado e adquirido para este trabalho. Para a comunicação entre sistema receptor e robô, foi desenvolvido um driver, obtendo-se as saídas de relés do sistema receptor e tratando-as com o auxílio de um Arduino Due. O programa desenvolvido em Arduino transforma os sinais obtidos do controle em uma mensagem ROS no padrão sensor_msgs/Joy.

\subsubsection{Bracelete de Eletromiografia}

Para obter mais informações da intenção do usuário uma vez que os comandos do joystick não possuem uma escala contínua de velocidades, foi utilizado um bracelete de eletromiografia comercial denominado Myo Armband. Este bracelete possui 8 eletrodos capazes de realizar uma eletromiografia de superfície em antebraços e, através de técnicas matemáticas, pode detectar alguns gestos padrão executados por uma pessoa. Possui também uma Unidade de Medição de Inércia (IMU - Inertial Measurement Unit), que mede os 3 ângulos de Euler [Krishnan et al. 2018].

\subsection{Modos de Autonomia e Autonomia Deslizante}

Conforme [Desai and Yanco 2005], na robótica os modos de autonomia geralmente se apresentam divididos em quatro: Manual, Compartilhado, Supervisório e Autônomo. Para o Robô de Inspeção utilizado nesta dissertação, foram propostos e implementados estes modos, de maneira a propiciar conforto e segurança na operação mas também o controle total do operador em casos necessários. Um método inteligente de seleção do melhor modo de autonomia também foi desenvolvido, que será explicado nesta seção.

Para realizar a Autonomia Deslizante ou Variável, que é troca de nível de autonomia durante a operação sem interferência do operador, foi desenvolvido um controlador Fuzzy do tipo Mamdani, operador de implicação como mínimo, operador de agregação selecionado como máximo, com método de defuzzificação centroide, 4 entradas e uma saída. As 4 variáveis de entrada são: o nível dos eletrodos detectado pelo bracelete Myo, a unidade inercial do bracelete, a velocidade angular do joystick industrial e a posição do cordão de solda em relação ao centro do robô. A variável de saída é o nível de autonomia 
para o robô. De acordo com o valor da saída do controlador Fuzzy, os diferentes níveis de autonomia são alcançados.

Quando o valor de saída do controlador Fuzzy está no intervalo entre 0 e 1, o nível de autonomia do robô é ajustado para Manual. Neste modo, o operador tem total controle do robô de inspeção, podendo circular livremente sobre o tanque ou superfície a ser inspecionada. Este é o modo padrão a ser utilizado para posicionar o robô no tanque em um cordão de solda, para retirá-lo do tanque após o processo de inspeção ou para reposicionar o robô em caso de perda do seguimento do cordão de solda. Para movimentar o robô, o operador controla o joystick em conjunto com a rotação do braço para gerar um movimento mais fluido ao robô, como pode-se ver na Figura 1.

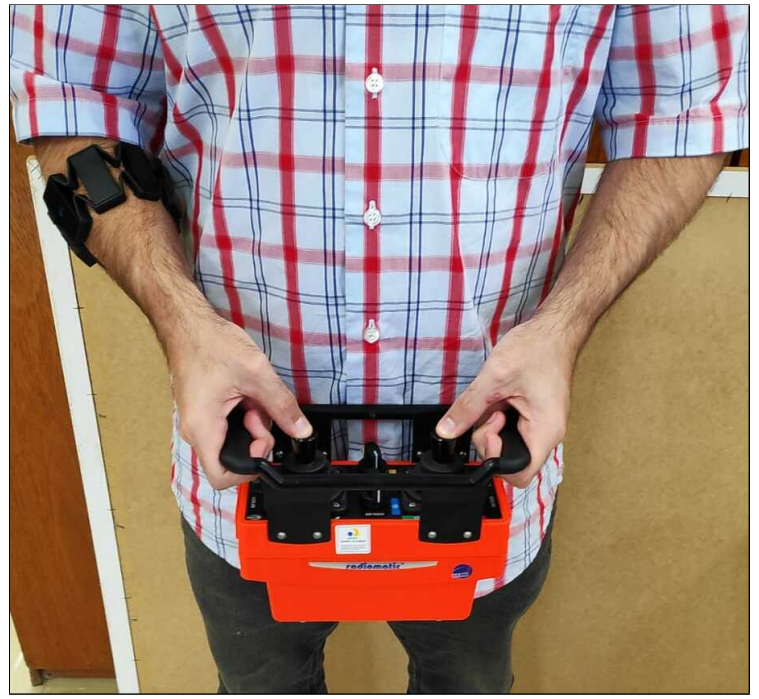

Figura 1. Controle do robô. Há uma fusão entre dados de um joystick industrial e um bracelete Myo para gerar os movimentos do robô.

Quando o valor da saída do controlador Fuzzy está dentro do intervalo entre 1 e 2, o nível é ajustado para Compartilhado. No modo Compartilhado, tanto o operador quanto o robô atuam em conjunto no comando de velocidades. A iniciativa mista é obtida com o operador atuando através do joystick e o bracelete Myo, e o robô, através do modo Autônomo. O grau de atuação de cada agente pode variar de 0 a $100 \%$, sendo o do outro agente a parcela complementar.

Caso a saída do controlador esteja no intervalo entre 2 e 3 , o modo selecionado é o Supervisório. Este modo compreende a operação do robô se orientando no cordão de solda de maneira autônoma e o comando de velocidade linear sendo operado de maneira manual. Desta forma, o robô não perde o cordão de solda de vista e o operador tem total controle sobre a velocidade linear, podendo avançar lentamente ou retornar em pontos que necessitem uma nova inspeção.

Por fim, caso a saída do controlador esteja dentro do intervalo entre 3 e 4, o modo selecionado será o Autônomo. Para compor o modo Autônomo, foi utilizado o trabalho de [Terres 2019], que consiste em uma interface de comunicação do sensor de perfil para obter os dados do sensor na mensagem padrão tipo sensor_msgs/LaserScan do ROS e um sistema de identificação do cordão de solda em relação ao robô. 


\section{Experimentos}

\subsection{Experimentos com os Modos de Autonomia}

Primeiramente os modos de autonomia foram validados em experimentos para comparação e análise. Nos experimentos o operador tinha como objetivo navegar pelo tanque de armazenamento com o robô o mais centralizado possível nos cordões de solda, de um ponto inicial A até um ponto final B e realizando 7 curvas, conforme a Figura 2. Os experimentos foram repetidos 5 vezes e, com o objetivo de medir-se a eficiência durante um experimento, foram medidos o tempo transcorrido e o valor do erro médio de alinhamento do cordão de solda em relação ao robô.

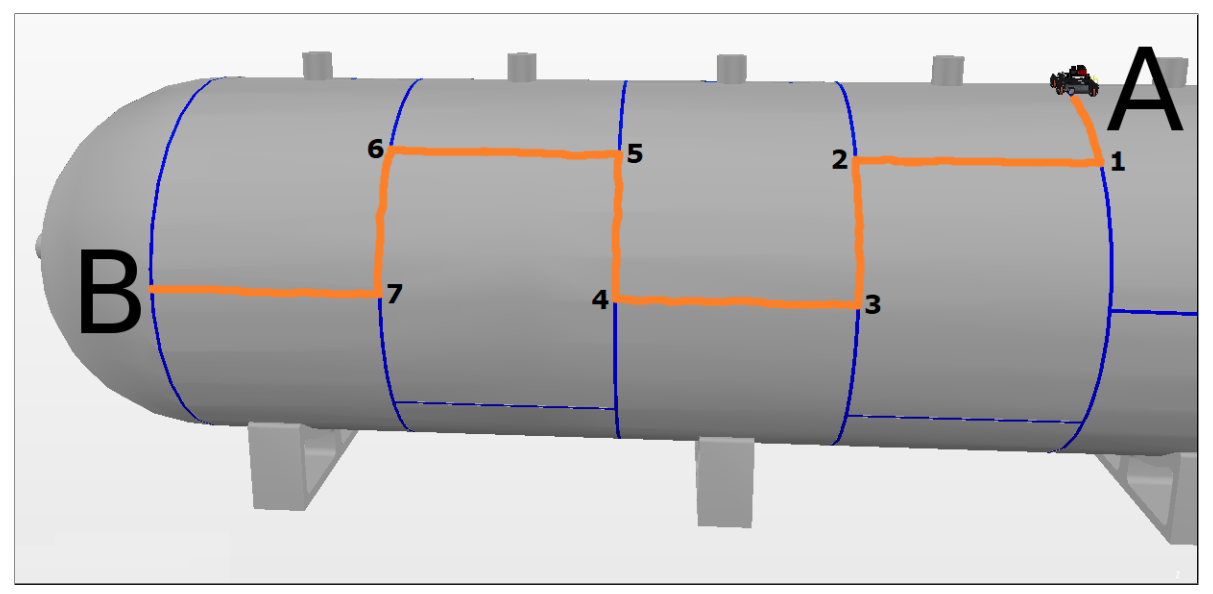

Figura 2. Objetivo de navegação do robô AlR-1 com diferentes Modos de Autonomia. $O$ ponto $A$ é a posição inicial do robô e o ponto $B$ é a posição final, na interseção entre os cordões de solda. Há 7 curvas a serem realizadas pelo robô, que percorre o trajeto na cor laranja. Fonte: Autoria própria.

\subsection{Experimentos com Autonomia Variável}

Para verificar a validade do sistema Fuzzy proposto, o mesmo experimento foi realizado com 5 participantes diferentes. Os participantes foram todos do sexo masculino, de 20 a 31 anos de idade, com alguma experiência em robôs móveis, mas nenhuma experiência prévia com este joystick e nem com o bracelete Myo. O protocolo adotado para os experimentos foi o seguinte: primeiramente, cada participante foi trazido separadamente para o computador com o simulador e a cena já abertos. Foi explicado o objetivo de navegar-se do ponto $\mathrm{A}$ ao ponto $\mathrm{B}$, no menor tempo possível e cobrindo a maior parte possível do cordão de solda, conforme a Figura 2. Em seguida, foi solicitado aos participantes que segurassem o joystick e vestissem o bracelete Myo. Na sequência, foram apresentados de maneira verbal a cada um dos participantes todos os comandos do joystick industrial e os movimentos de rotação medidos pelo bracelete. Foi então oferecido um tempo de 15 minutos para que cada participante pudesse se adaptar ao sistema, controlando o robô no modo Manual na mesma cena que realizariam o experimento. Passado este tempo, a cena no simulador foi reiniciada para a posição inicial, o controlador Fuzzy foi ativado e iniciou-se o experimento. Os resultados estão apresentados na Tabela 1.

Cada participante realizou o experimento somente uma vez para verificar a adaptabilidade do sistema a usuários novos com diferentes níveis de experiência. A informação 
Tabela 1. Experimentos realizados com Autonomia Variável.

\begin{tabular}{|c|c|c|c|c|c|c|c|c|}
\hline E. & Tempo (s) & \% Man. & \% Comp. & \% Sup. & \% Aut. & M. Aut. & Tr. & Erro \\
\hline 1 & 204.51 & 43.01 & 55.45 & 1.54 & 0.00 & 1.06 & 108 & 0.1032 \\
\hline 2 & 195.01 & 13.55 & 83.45 & 3.00 & 0.00 & 1.29 & 60 & 0.1019 \\
\hline 3 & 189.76 & 5.18 & 83.98 & 10.84 & 0.00 & 1.53 & 37 & 0.0907 \\
\hline 4 & 215.25 & 10.32 & 76.32 & 13.36 & 0.00 & 1.51 & 66 & 0.1029 \\
\hline 5 & 202.00 & 13.36 & 81.73 & 4.26 & 0.65 & 1.34 & 55 & 0.1068 \\
\hline
\end{tabular}

relevante é se o sistema é capaz de se adaptar e corrigir operadores com diferentes níveis de experiência. Se os participantes treinassem para melhorar sua habilidade antes dos experimentos, seria mais difícil de verificar a adaptabilidade do sistema. A primeira coluna desta tabela indica o número do experimento. Após tem-se o tempo transcorrido para concluir a tarefa e a porcentagem de tempo que o sistema Fuzzy selecionou os modos de autonomia, na ordem: Manual, Compartilhado, Supervisório e Autônomo. Nota-se que o modo Autônomo quase não foi acionado, pois este é mais uma salvaguarda para evitar acidentes com o sistema caso o operador esteja controlando o robô de forma completamente errada. Após estes dados vê-se a média aritmética do nível de autonomia durante o experimento. Quanto mais baixo este valor, mais o sistema deixou o usuário controlar o robô, indicando que o usuário tem mais experiência com o controle do robô. $\mathrm{Na}$ penúltima coluna está o número de transições entre os modos de autonomia e por fim, o erro médio de alinhamento do cordão de solda em relação ao robô durante a realização do experimento.

Como exemplo, o quinto experimento será utilizado. A Figura 3 demonstra o percurso realizado.

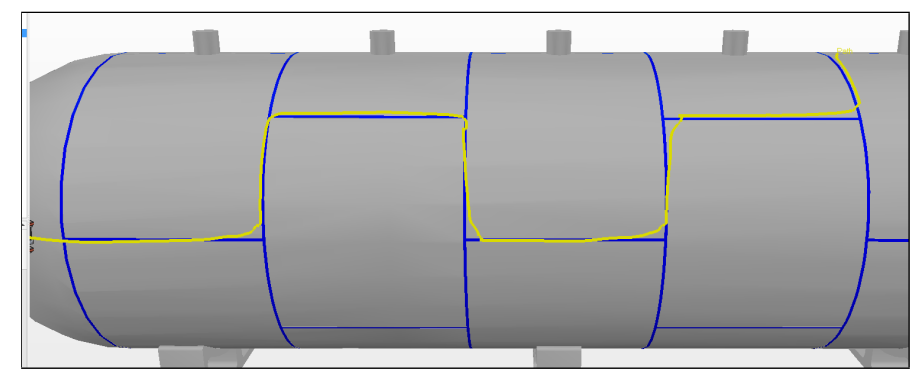

Figura 3. Experimento realizado com Autonomia Variável.

Percebe-se que em algumas curvas o percurso possui ângulos bruscos devido ao fato da autonomia estar sendo mudada de maneira online, e nestes pontos de curvas há também picos de erro do alinhamento do cordão de solda, fazendo com que o sistema aumente sua autonomia para buscar um melhor seguimento do cordão de solda. Estes valores podem ser confirmados vendo a Figura 4.

\subsection{Resultados e Discussão}

Para análise foi tirada a média dos resultados alcançados e estão apresentados na Tabela 2.

Considerando-se apenas os experimentos com o Modo de Autonomia fixo, percebe-se que o Modo Manual obteve o pior resultado na média do erro durante o experimento. 


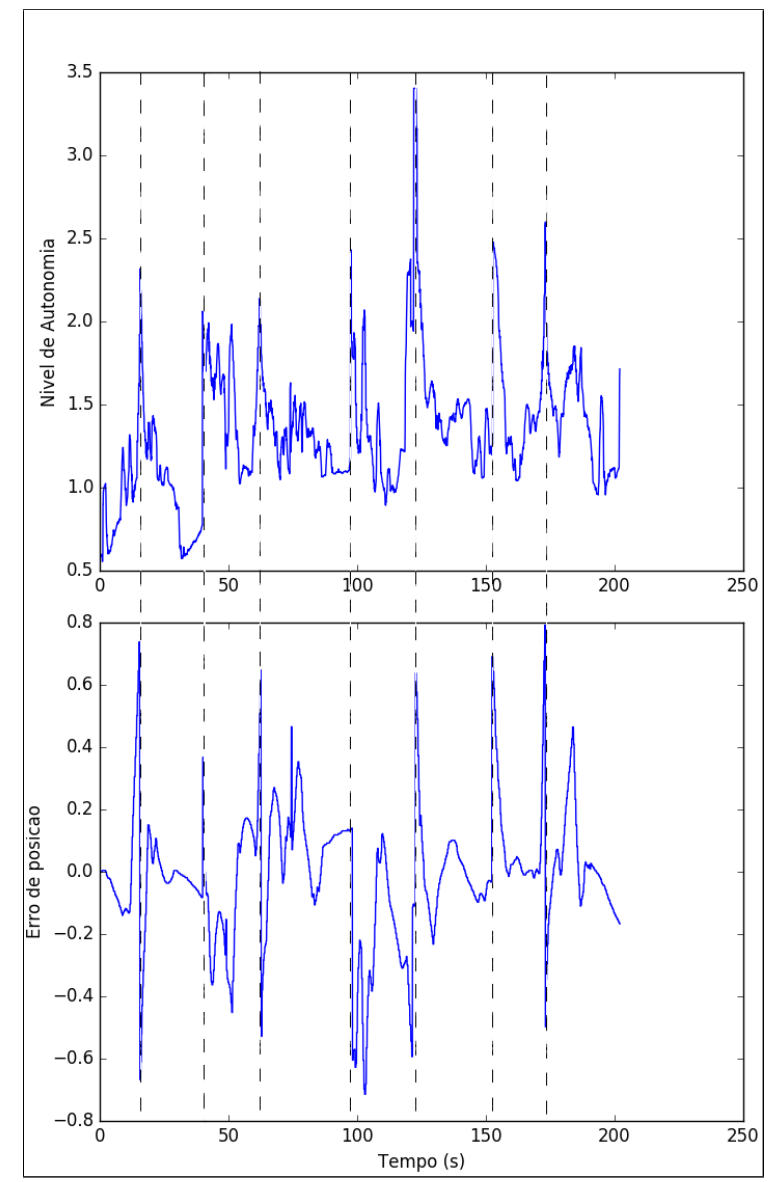

Figura 4. Acima, o valor do nível de autonomia do robô ao longo do experimento. Abaixo, o erro de alinhamento. Linhas tracejadas indicam que nos instantes onde há picos de erro a autonomia aumenta.

Tabela 2. Resultados dos Experimentos.

\begin{tabular}{|c|c|c|}
\hline Modo de Autonomia & Média do erro de alinhamento (m) & Média do tempo (s) \\
\hline Supervisório & 0.0922 & 158.28 \\
\hline Variável & 0.0982 & 204.09 \\
\hline Compartilhado & 0.1019 & 185.26 \\
\hline Autônomo & 0.1054 & 158.32 \\
\hline Manual & 0.1415 & 175.91 \\
\hline
\end{tabular}

O modo Compartilhado apresentou uma melhora de $28 \%$ em relação ao erro do modo anterior, com um aumento de $6 \%$ no tempo da tarefa. O tempo extra transcorrido deve-se ao fato das correções de orientação pelo sistema autônomo.

Percebe-se a dificuldade de no modo Manual, manter-se no cordão de solda durante os trechos retos. Isto é representado por momentos onde o erro é praticamente zero nos modos Autônomo e Supervisório. Estes momentos, porém, não são encontrados no modo Manual e Compartilhado. Em todos os modos, porém, há grandes picos de valores de erro, que representam os momentos onde o robô está realizando uma curva e não há possibilidade, pela topologia do robô AIR-1, de suprimir estes valores. Quando o robô está se aproximando de uma curva, o cordão de solda que está sendo medido antes da 
curva deixará de ser medido para ocorrer a troca por outro cordão de solda, que será medido pelo sensor de perfil com um valor alto pela aproximação do robô pelo lado. São nestes momentos que ocorrem os picos observados nos gráficos.

Nos modos Supervisório e Autônomo observou-se os melhores tempos e com valores muito parecidos, com uma ligeira vantagem para o modo Autônomo. O modo Supervisório porém, foi melhor em relação ao erro acumulado durante a tarefa pois, com o auxílio do operador, as curvas são mais suaves e passam mais próximas ao cordão de solda em relação ao modo Autônomo. A dificuldade da realização das curvas no modo Autônomo é o acompanhamento do cordão de solda, fazendo até mesmo com que o robô se perca em alguns momentos, devido à curvatura do tanque e a ação da gravidade. As rotinas de curva teriam que ser modificadas para cada situação diferente. O sistema autônomo porém, falha algumas vezes nesta tarefa, passando do ponto onde o cordão de solda pode ser identificado e perdendo-se no tanque. Já nos outros modos esta falha nunca ocorre, pois o operador é capaz de ver este erro ocorrendo e corrigi-lo com o controle. Através dos experimentos vê-se claramente os benefícios do sistema autônomo do robô para manter-se no cordão de solda em trechos retos e do operador nos trechos de curva, onde cada situação é diferente.

Já no modo de Autonomia Variável com o controlador Fuzzy, obteve-se o pior tempo pois houve uma variação muito grande de tempo entre os participantes e, como no modo Compartilhado, o maior tempo é devido às alterações e correções do sistema, pois como pode-se ver pela média do erro, o modo de Autonomia Variável ficou muito semelhante ao melhor desempenho dos experimentos com a autonomia fixa, que foi o Supervisório.

Analisando-se melhor a Tabela 1, pode-se perceber uma variação grande entre o nível dos participantes nos experimentos. A média da saída do sistema, representada na sétima coluna como "M. Aut."ou média de autonomia da saída do sistema, indica o nível de habilidade que o sistema Fuzzy identifica do operador, e quanto menor seu valor, mais de acordo com o sistema modelado a pessoa está agindo. No experimento 1 percebe-se que o sistema deixou a pessoa atuar pelo modo Manual por $43 \%$ do tempo, indicando que esta pessoa possui um bom nível de controle para o sistema. Já no experimento 3, apenas $5.18 \%$ do tempo o robô esteve no modo Manual, porém o tempo total da tarefa foi menor, indicando talvez um operador mais apressado porém sem tanta habilidade. O experimento 5 foi o único que teve algum momento no modo Autônomo, em apenas $0.65 \%$ do tempo da tarefa, no instante crítico de curva com subida citado anteriormente. O número de transições entre os modos não mostrou ser um indicador razoável para medir a habilidade do operador ou o erro do sistema. Apenas percebeu-se que está relacionado com um nível de habilidade que fica oscilando entre dois modos.

O dado mais interessante porém desta tabela foi a percepção de que, mesmo com uma variação da duração da tarefa de quase 15 segundos ou variação da média da autonomia de 0.47 pontos, com participantes ficando de $5.18 \%$ a $43.01 \%$ no modo Manual, todos os experimentos mostraram um erro baixo e muito próximo entre os participantes. Esta é a constatação mais importante, pois valida a atuação do controlador Fuzzy para corrigir a atuação de diferentes operadores um erro similar aos modos Supervisório e Autônomo. 


\section{Conclusão}

O objetivo deste trabalho foi desenvolver uma Interface Humano-Robô com fusão de sensores e estratégias inteligentes em um robô escalador de inspeção de tanques de armazenamento e vasos de pressão.

A interface desenvolvida se fez necessária para que diferentes operadores com diferentes níveis de habilidade e experiência possam controlar o robô durante a tarefa de inspeção com alto grau de seguimento do cordão de solda.

Uma pesquisa sobre Interação Humano-Robô, Autonomia e Autonomia Deslizante ou Variável foi realizada e o estado da arte nestas áreas foi pesquisado. Baseado nestas pesquisas, verificou-se que as abordagens na literatura variam em relação a aplicação, e que no contexto da robótica os níveis de Autonomia geralmente são divididos entre Manual, Compartilhado, Supervisório e Autônomo.

No capítulo 3 estes modos foram desenvolvidos e aplicados através da fusão de sensores. Um joystick industrial de radiofrequência foi projetado e um driver desenvolvido para controlar o robô, em conjunto com um bracelete eletromiográfico que mede gestos, ângulos de rotação e o nível de enrijecimento muscular. Estas duas entradas foram fundidas para gerar uma movimentação mais fluida e natural do robô. Os níveis mais elevados de Autonomia contaram também com o seguimento do cordão de solda, medido por um sensor de perfil e um controlador Fuzzy apresentado no trabalho de [Terres 2019]. Após os modos terem sido implementados separadamente, um controlador Fuzzy foi desenvolvido para obter-se o melhor nível de autonomia durante a operação, fazendo com que o robô se adapte ao operador que o esteja operando. Este controlador tem como entradas a posição do cordão de solda em relação ao robô medido pelo sensor de perfil, os comandos do joystick e também do bracelete eletromiográfico.

A validação do sistema se deu através de experimentos virtuais, com o uso do simulador V-REP. No ambiente virtual, foram utilizados uma cena contendo um tanque de armazenamento com os cordões de solda e o modelo do robô de inspeção AIR-1 para percorrer uma rota simulando a tarefa de inspeção. Experimentos foram realizados com os modos de autonomia separados para verificar a validade de seu uso, tomando-se como métricas o tempo de execução da tarefa e o erro médio de alinhamento do cordão de solda. Para os experimentos com Autonomia Variável, 5 participantes com diferentes níveis de habilidade controlaram o robô pelo mesmo percurso, tentando ao melhor de suas habilidades manter o robô o mais próximo possível ao cordão de solda. Foi verificado que durante os experimentos com Autonomia Variável, apesar dos participantes terem diferentes níveis de habilidade, o erro médio de alinhamento se manteve muito próximo, demonstrando que o sistema se adapta aos diferentes usuários.

Este trabalho permitiu as seguintes publicações:

- PALAR, P. S.; DE OLIVEIRA, A. S.; TERRES, V. V. Human-Robot Interface for Embedding Sliding Adjustable Autonomy Methods. Sensors. 2020; 20(20):5960. https://doi.org/10.3390/s20205960

- PALAR, P. S.; DE OLIVEIRA, A. S.; TERRES, V. V.; RAMOS, J. E. Automated Inspection of Pressure Vessels through a Climbing Robot with Sliding Autonomy. In: In Latin American Robotics Symposium / Brazilian Symposium of Robotics, Out 2019. Rio Grande. 


\section{Referências}

Beavers, G. and Hexmoor, H. (2004). Types and Limits of Agent Autonomy. Agents and Computational Autonomy. Potential, Risks, and Solutions, pages 95-102.

Desai, M. and Yanco, H. A. (2005). Blending human and robot inputs for sliding scale autonomy. Proceedings - IEEE International Workshop on Robot and Human Interactive Communication, 2005:537-542.

Espinoza, R. V. (2014). Estimador de adesão de um robô escalador com rodas magnéticas. Mestrado em engenharia elétrica e informática industrial, Universidade Tecnológica Federal do Paraná, Curitiba.

Goodrich, M. A. and Schultz, A. C. (2007). Human-Robot Interaction: A Survey. Foundations and Trends ${ }^{\circledR}$ in Human-Computer Interaction, 1(3):203-275.

Jiang, S. and Arkin, R. C. (2016). Mixed-Initiative Human-Robot Interaction: Definition, Taxonomy, and Survey. Proceedings - 2015 IEEE International Conference on Systems, Man, and Cybernetics, SMC 2015, pages 954-961.

Krishnan, K. S., Saha, A., Ramachandran, S., and Kumar, S. (2018). Recognition of human arm gestures using Myo armband for the game of hand cricket. Proceedings - 2017 IEEE 5th International Symposium on Robotics and Intelligent Sensors, IRIS 2017, 2018-Janua:389-394.

Lasota, P. A., Fong, T., and Shah, J. A. (2017). A Survey of Methods for Safe HumanRobot Interaction. Foundations and Trends in Robotics, 5(3):261-349.

Losey, D. P., McDonald, C. G., Battaglia, E., and O’Malley, M. K. (2018). A Review of Intent Detection, Arbitration, and Communication Aspects of Shared Control for Physical Human-Robot Interaction. Applied Mechanics Reviews, 70(1):010804.

Rosa, A. B. and Gnoatto, R. (2015). Reprojeto e construção de protótipo de um robô de inspeção de cordões de solda em superfícies metálicas verticais e esféricas (segunda geração). Trabalho de conclusão de curso, Universidade Tecnológica Federal do Paraná, Curitiba.

Rovani, A. (2013). Desenvolvimento do prtótipo de um robô para inspeção de cordões de solda em superfícies metálicas verticais. Trabalho de conclusão de curso, Universidade Tecnológica Federal do Paraná, Curitiba.

Tellaeche, A., Maurtua, I., and Ibarguren, A. (2015). Human robot interaction in industrial robotics. Examples from research centers to industry. 2015 IEEE 20th Conference on Emerging Technologies \& Factory Automation (ETFA), pages 1-6.

Terres, V. d. V. (2019). Controle de seguimento de cordão de solda para um robô de inspeção. Trabalho de conclusão de curso, Universidade Tecnológica Federal do Paraná, Curitiba. 